\title{
Erratum to: Global Supply Chain and Operations Management
}

\author{
Dmitry Ivanov, Alexander Tsipoulanidis, and Jörn Schönberger
}

(C) Springer International Publishing Switzerland 2017

D. Ivanov et al., Global Supply Chain and Operations Management, Springer Texts in Business and Economics,

DOI 10.1007/978-3-319-24217-0

\section{DOI 10.1007/978-3-319-24217-0_15}

In the Front matter page X, the last paragraph stated "This book is accompanied by a free Web site www.supply-chainmanagement.de".

This website link has been updated to www.global-supply-chain-management.de.

The updated online version of the original book can be found at http://dx.doi.org/10.1007/978-3-319-24217-0 